\title{
Oscillations Damping and Maximization of Wind Energy Using A Fractional Order PID Controller
}

\author{
TAREK A. BOGHDADY ${ }^{\mathrm{a}}$, SAUD N. ALAJMI ${ }^{\mathrm{b}}$, M. A. MOUSTAFA HASSAN ${ }^{\mathrm{c}}$, A. A. SEIF ${ }^{\mathrm{d}}$ \\ Department of Electrical Engineering, Faculty of Engineering \\ Cairo University, Giza, EGYPT
}

\begin{abstract}
Renewable energy resources are the favorable solution for the coming energy. So, a great interest has been paid in the last decades for developing and utilizing renewable energy resources such as wind energy. As it has a large energy content and, particularizes with the availability, the major problems of it is represented in unmatched with load demand because of the intermittency and fluctuation of natural conditions. Different optimization methods are presented and discussed like Genetic Algorithm (GA), Grey Wolf Optimization (GWO). These optimization methods are used to obtain the optimum parameters for Proportional Integral (PI) controller and the fractional-order PI. The PI and FOPI parameters' gains are optimized and obtained. For more clarification for the wind farm performance in the case of using PI controller and fractional-order PI, a threephase and single-phase fault are applied to the system. The performance analysis for the system due to these faults is obtained and discussed.
\end{abstract}

Key-Words: - Genetic Algorithm, Grey Wolf Optimization, PMSG, Renewable energy, Wind turbine.

Received: March 19, 2021. Revised: January 9, 2022. Accepted: January 24, 2022. Published: February 16, 2022.

\section{Introduction}

Wind energy is one of the important types of renewable energy as it is clean, inexhaustible and has low running cost [1-3].

Damping the oscillations and increasing the extractable power of wind turbines are challenging tasks. Wind power plants are extremely complex systems, and they always rely on automatic control for satisfactory operation. To operate safely and efficiently, the need for a robust control is increased as there are many uncertainties caused by linearization, noise accompanied with measurements, and parameters variation with time.

Increasing interest has been directed to develop wind energy generation. The electrical controller can achieve a lot of objectives especially in wind turbines that have variable speeds [4-8].

The PI controller is very common in many industrial applications as it is reliable, familiar, and easy in implementation. The challenging task is how to tune the PI parameters. Using of conventional techniques were not accurate in tuning the PI parameters. Ziegler-Nicholas was used depending on loop testing [9, 10]. While, today the focus is on intelligent control as Artificial Neural Network (ANN) controller, Fuzzy Logic Controller (FLC), and Evolutionary Algorithms (EA) based controller [11].
There are many evolutionary algorithms such as Genetic Algorithms (GA) based on natural selection, Particle Swarm Optimization (PSO) based on the social behavior of bird flocking and fish schooling, and Harmony Search (HS) based on music improvisation process [12-17].

The first method that is being used here is GA. It is one of the most popular metaheuristic methods because it is a robust and reliable method; it is based on Darwin's principles of "the survival of the fittest". The large fitness according to the optimization process has the superior probability to generate a new generation.

The second method that is being used here is Grey Wolf Optimization (GWO) [18], which is a recently developed EA in the scientific search.

This paper is organized as follows. A comparison between the optimization techniques is carried out in section 2 to select one of them for PI and FOPI tunning problems. Section 3 presents the electrical model of the wind power plant, simulation, and discussion of PMSG in normal and abnormal cases are presented. Finally, Section 4 summarizes the simulation results.

\section{Testing the Optimization Techniques}


Improving the controller performance by tracing the reference signal (i.e. reducing the error between the measured and reference signals) in an industrial process is considered an important task by using PID controller, while finding the optimum parameters value of PID controller is considered a very difficult task. Most PID tuning techniques use conventional methods such as frequency response which requires considerable technical experience to apply those formulas. Due to their difficulties, PID controller parameters are rarely tuned optimally.

The aim here is to test GWO and carry out a comparison between its performance with PSO, GA, and Linearized Biogeography-Based Optimization (LBBO) [19-20]. The squared error integral criteria is the objective function to be minimized in the step response of a process which is cascaded with a PID controller as shown in Figure 1 by tuning the proportional gain $(\mathrm{Kp})$, integral gain $(\mathrm{Ki})$, and differential gain $(\mathrm{Kd})$ using MATLAB/SIMULINK.

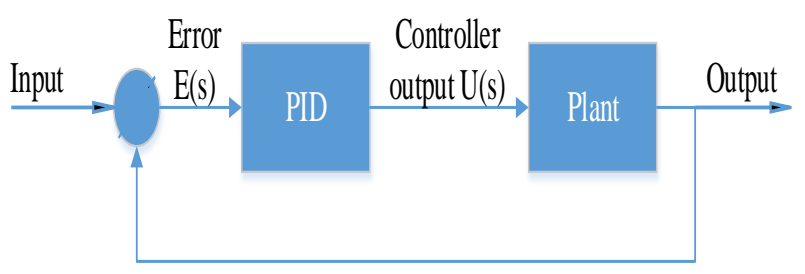

Fig. 1: Block diagram of the tested systems

Table 1 shows seven transfer functions of benchmark systems of different orders that will be used here for testing GWO performance. The tuned gains obtained by using GWO algorithm are given in Table 1, while Table 2 presents the tuned gains that have been obtained using three algorithms.

For the first plant, the values of $\mathrm{Kp}, \mathrm{Ki}$, and $\mathrm{Kd}$ founded by GWO, GA, and LBBO are nearly the same, while the PSO solution is drifted by about $40 \%$ of the values found by other algorithms. This is reflected in the objective function values as shown in Table 2 where PSO has the worst objective function value. The results of the three algorithms (GWO, GA, and LBBO) applied to plants 2, 4, and 6 are nearly the same optimized value. Plant 4 , it is shown that the PSO results in unstable controller performance, while approximately the same results (i.e controller response) are obtained using the other three algorithms. Also, the GWO obtained results for plants 3,5, and 7 are much better than the other algorithms, the GWO has approximately a reduction from $21 \%$ to $45 \%$ in the optimized value.

Table 3 indicates that GWO produces better results with a lower number of objective function evaluation. The unit step response for the test plants using the four optimization algorithms PSO, GA, LBBO, and GWO for tuning the PID parameters are shown in Figure 2 through Figure 8. In all cases, GWO has the fastest settling time.

Table 1 . The tuned values obtained by GWO

\begin{tabular}{|c|c|c|c|c|}
\hline \multirow{2}{*}{$\begin{array}{l}\text { Plant } \\
\text { No. }\end{array}$} & \multirow{2}{*}{ Transfer function } & \multicolumn{3}{|c|}{ GWO } \\
\hline & & $\mathrm{Kp}$ & $\mathrm{Ki}$ & $\mathrm{d}$ \\
\hline 1 & 5 & 1.423 & 0 & 1.2030 \\
\hline 2 & $S+5$ & 30 & 0 & 18.985 \\
\hline 3 & $\frac{300(S+100)}{S(S+10)(S+40)}$ & 25 & 0 & 03045 \\
\hline 4 & $\frac{6}{S^{4}+3 S^{3}+4 S^{2}+3 S+}$ & 0.319 & 0.102 & 0.4333 \\
\hline 5 & $\frac{250 S+500}{S^{3}+12 S^{2}+100 S+10}$ & 8.423 & 7.265 & 0.2017 \\
\hline 6 & $\frac{S+5}{S^{4}+17 S^{3}+60 S^{2}+5 S}$ & 15 & 1.1761 & 12.387 \\
\hline 7 & $\frac{1}{S^{2}+0.1 S+1}$ & 10 & 2.500 & 2.932 \\
\hline
\end{tabular}

Table 2. The tuned values for LBBO, GA, PSO.

\begin{tabular}{cccccccccc}
\hline \multirow{2}{*}{$\begin{array}{c}\text { Plant } \\
\text { No. }\end{array}$} & \multicolumn{3}{c}{ LBBO } & \multicolumn{3}{c}{ GA } & \multicolumn{4}{c}{ PSO } \\
\cline { 2 - 10 } & $\boldsymbol{K}$ & $\boldsymbol{K} \boldsymbol{i}$ & $\boldsymbol{K} \boldsymbol{d}$ & $\boldsymbol{K} \boldsymbol{p}$ & $\boldsymbol{K} \boldsymbol{i}$ & $\boldsymbol{K} \boldsymbol{d}$ & $\boldsymbol{K} \boldsymbol{p}$ & $\boldsymbol{K} \boldsymbol{i}$ & $\boldsymbol{K} \boldsymbol{d}$ \\
\hline $\mathbf{l}$ & 1.38 & 0.05 & 1.04 & 1.00 & 0 & 1.00 & 0.56 & 0 & 0.62 \\
$\mathbf{2}$ & 29.68 & 0 & 19.07 & 25.85 & 0 & 12.65 & 4.36 & 0 & 14.41 \\
$\mathbf{3}$ & 24.20 & 0.99 & 1.00 & 24.99 & 0.286 & 10.8 & 0.17 & 0 & 0.03 \\
$\mathbf{4}$ & 0.259 & 0.11 & 0.40 & 0.21 & 0.1 & 0.4 & 0.1 & 0.48 & 15.92 \\
$\mathbf{5}$ & 4.23 & 3.34 & 0.129 & 0.99 & 1.03 & 0 & 0.44 & 0.18 & 0.21 \\
$\mathbf{6}$ & 14.99 & 0.82 & 13.98 & 13.98 & 1.00 & 13.85 & 3.78 & 0.12 & 13.00 \\
$\mathbf{7}$ & 6.05 & 1.11 & 5.02 & 4.01 & 0.97 & 3.00 & 0.72 & 1.11 & 3.58 \\
\hline
\end{tabular}


Table 3. Objective functions values obtained by GWO, LBBO, GA and PSO (the lowest value in each row is shown in black boldface)

\begin{tabular}{ccccc}
\hline \multirow{2}{*}{$\begin{array}{c}\text { Plant } \\
\text { No. }\end{array}$} & \multicolumn{4}{c}{ Best Min. Objective Function } \\
\cline { 2 - 5 } & GWO & LBBO & GA & PSO \\
\hline 1 & 1.102 & 1.3132 & 1.9746 & 1.9520 \\
2 & 0.9523 & 0.6497 & 0.6505 & 2.2400 \\
3 & 0.0010 & 0.0105 & 0.216 & 0.1469 \\
4 & 1.8773 & 1.9392 & 2.1500 & 21.7600 \\
5 & 0.0212 & 0.0239 & 0.3661 & 0.3697 \\
6 & 0.8867 & 0.9078 & 0.9513 & 2.5600 \\
7 & 0.2153 & 0.2952 & 0.5374 & 1.5330 \\
\hline
\end{tabular}

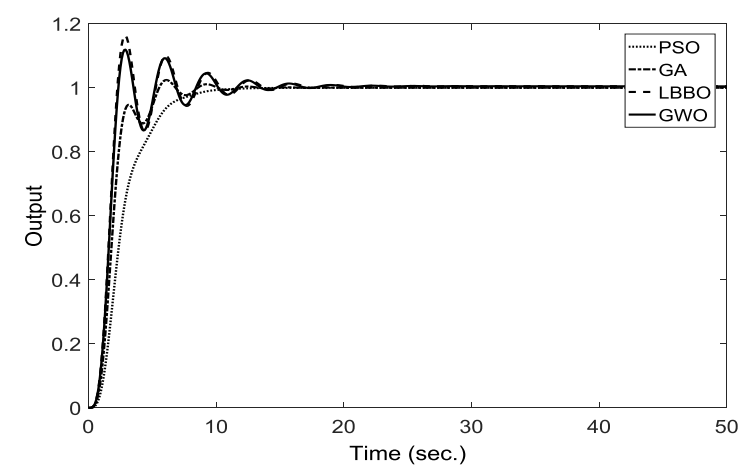

Fig. 2: Plant number 1 output response.

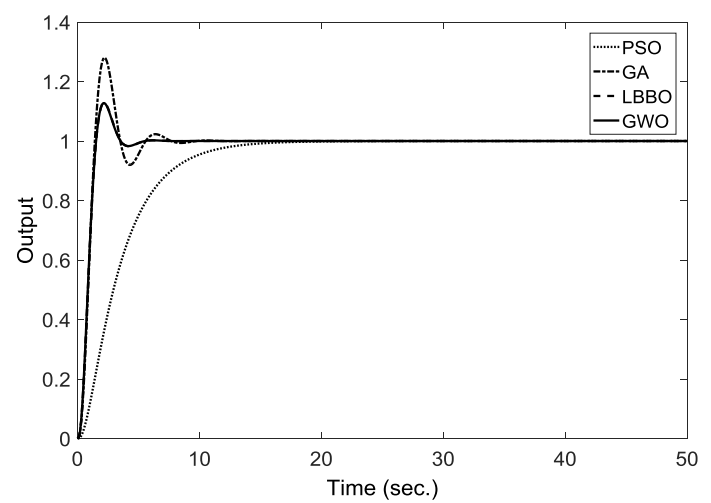

Fig. 3: Plant number 2 output response.

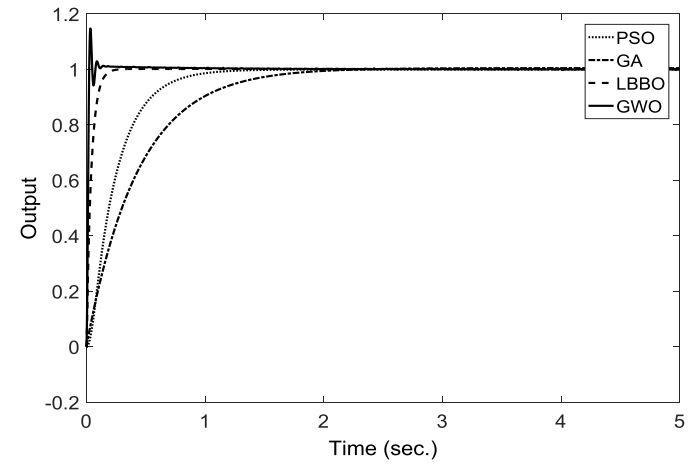

Fig. 4: Plant number 3 output response.

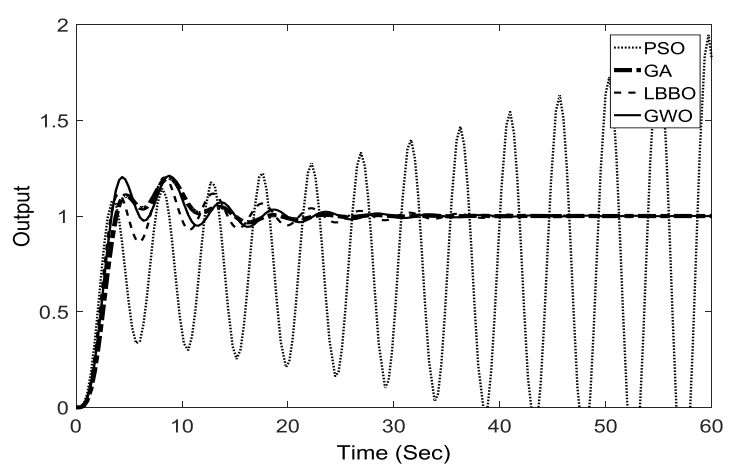

Fig. 5: Plant number 4 output response

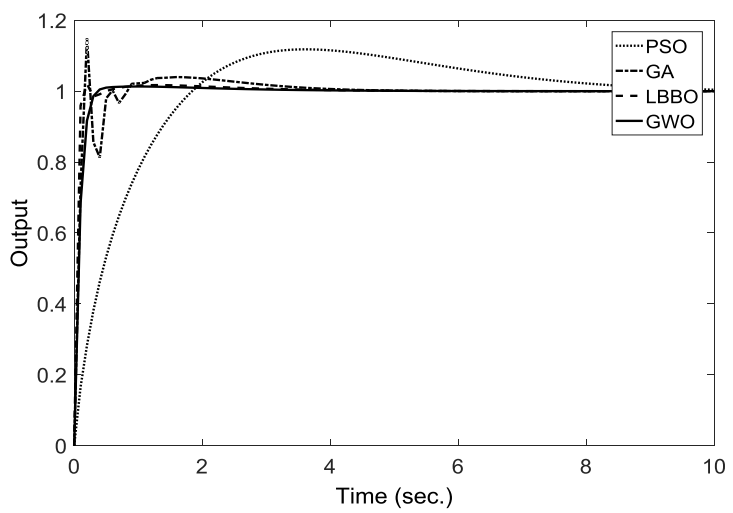

Fig. 6: Plant number 5 output response.

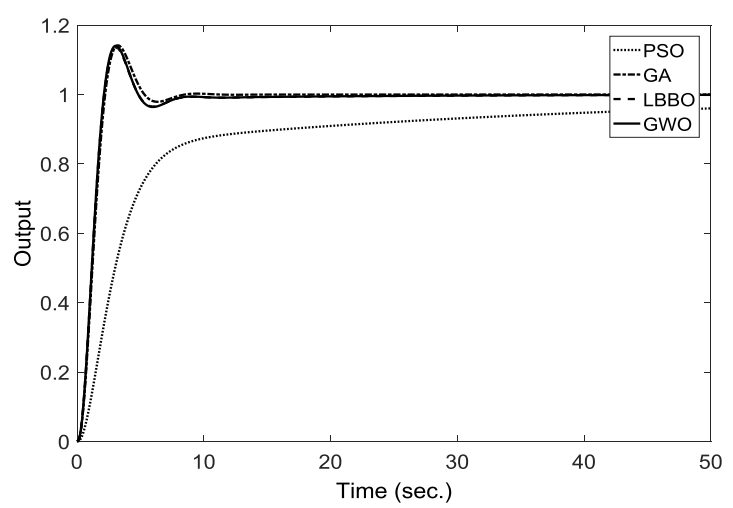

Fig. 7: Plant number 6 output response.

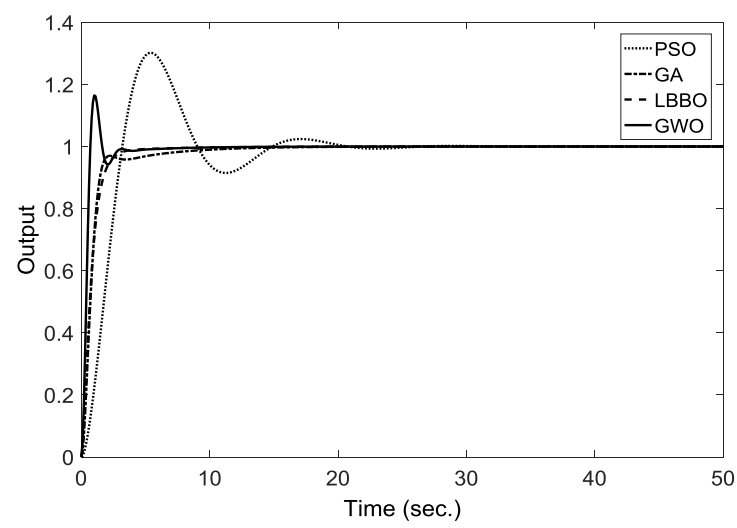

Fig. 8: Plant number 7 output response. 


\section{System Description and Modeling}

A direct-drive PMSG wind turbine is shown in Figure 9. The PMSG output power is fed to the utility side through generator side converter with a DC link than a grid side converter.

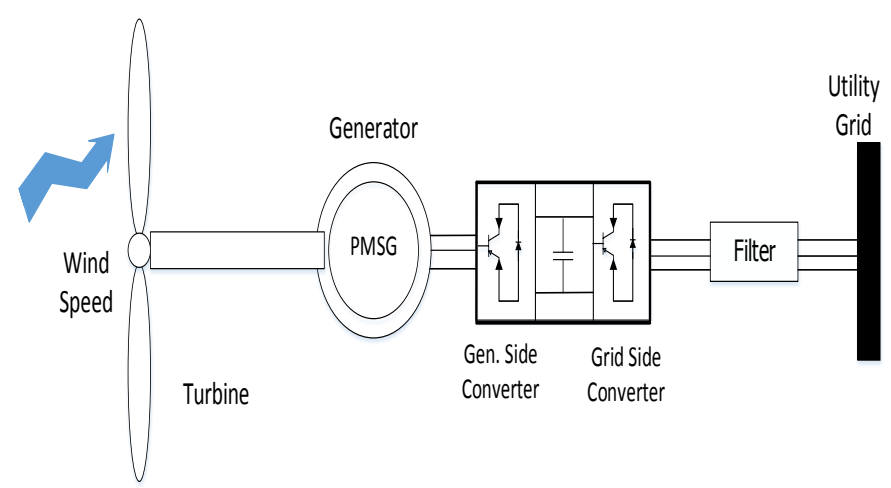

Fig. 9: PMSG wind energy system.

\subsection{Modeling of the Wind Turbine}

The power coefficient $(\mathrm{Cp})$ depend on the tip-speed ratio $(\lambda)$ and the pitch angle $(\beta)$, and it can be calculated for both fixed and variable speed wind turbine by equation (1) [21] by:

$C_{p}=C_{1}\left(C_{2}\left(\frac{1}{\lambda+0.08 \beta}-\frac{0.035}{\beta^{3}+1}\right)-C_{3} \beta-\right.$

$\left.C_{4}\right) e^{-C_{5}\left(\frac{1}{\lambda+0.08 \beta}-\frac{0.035}{\beta^{3}+1}\right)}+C_{6} \lambda$

where $C_{1}$ to $C_{6}$ are $[0.5176,116,0.4,5,21,0.0068]$. The peak value of $\mathrm{Cp}$ is obtained at $\beta=0^{\circ}$ and $\lambda$ opt. As stated in equation 1 the coefficient of performance for this turbine depends on the tip speed ratio $\lambda$ and pitch angle $\beta$ with 6 constants $\left(C_{1}\right.$ to $\mathrm{C}_{6}$ )

\subsubsection{Modeling of PMSG}

The PMSG equations are given in d-q frame as [22]:

$v_{d s}=R_{s} i_{d s}+L_{d s} \frac{d i_{d s}}{d t}-\omega_{r} L_{q s} i_{q s}$

$v_{q s}=R_{s} i_{q s}+L_{q s} \frac{d i_{q s}}{d t}+\omega_{r} L_{d s} i_{d s}+\omega_{r} \psi_{f}$

$T_{e}=p\left(\psi_{f} i_{q s}+\left(L_{d s}-L_{q s}\right) i_{d s} i_{q s}\right.$

Where $v_{d s}$ and $v_{q s}$ are the direct and quadrature components of the stator voltage, $R_{S}$ is the stator resistance, $i_{d s}$ and $i_{q s}$ are the direct and quadrature components of the stator currents, $L_{d s}$ and $L_{q s}$ are the direct and quadrature components of the stator self-inductance, $\omega_{r}$ is the electrical angular speed, and $\psi_{f}$ is the permanent magnet rotor magnetic flux, while the grid voltage are given in the (d-q) frame that is rotating with the angular frequency $\omega$ by:

$$
\begin{aligned}
& v_{d}=R_{g f} i_{d}+L_{d} \frac{d i_{d}}{d}-L_{q} i_{q}+E_{s} \\
& v_{q}=R_{g f} i_{q}+L_{q} \frac{d i_{q}}{d t}+\omega L_{d} i_{d}
\end{aligned}
$$

Where $R_{g f}$ is the filter resistance which is located between the grid side converter and the grid, $i_{d}$ and $i_{q}$ are the direct and quadrature components of the grid side converter output currents, $L_{d}$ and $L_{q}$ are the direct and quadrature components of the filter inductance, and $E_{S}$ is the maximum grid phase voltage.

\subsubsection{Generator Side Converter Control}

Its objective is to control the speed of the PMSG by Field oriented control (FOC) for achieving variable speed operation with maximum power point tracking control. This controller consists of three PI controllers; the rotor speed controller while the others controller for direct and quadrature axis currents.

\subsubsection{Grid Side Converter Control}

This controller's aim is to control the reactive power fed to the utility and the DC link voltage. Also, FOC controller is applied to the grid side converter. This controller requires 4 PI controllers, two for the currents while the others for the reactive power and DC link voltage.

\subsection{Simulation Results}

Simulation is done for 1.5 MW PMSG using MATLAB/SIMULINK as depicted in Figure 10, the parameters' values of PMSG are listed in [23, 24]. By multiplying the base value with the PU value, the actual value can be gotten. Here are the base values [23]:

$$
\begin{gathered}
I_{b}=\frac{P_{b}}{3 V_{b}}, Z_{b}=\frac{V_{b}}{I_{b}}, \omega_{b}=2 \pi f_{b}, \omega_{b m}=\frac{\omega_{b}}{\mathrm{P}}, \\
L_{b}=\frac{Z_{b}}{\omega_{b}}, C_{b}=\frac{1}{\omega_{b} Z_{b}}, T_{b}=\frac{P_{b}}{\omega_{b m}}, J_{b}=\frac{2 P_{b} \mathrm{P}^{2}}{\omega_{b}^{2}}, K_{b}= \\
\frac{2 P_{b} \mathrm{P}^{2}}{\omega_{b}}, \psi_{r b}=\frac{\sqrt{2} V_{b}}{\omega_{b}}
\end{gathered}
$$

Where the subscript " $b$ " means the base value; I, $\mathrm{V}, \mathrm{P}, \mathrm{f}$ are the current, voltage, power, and frequency, respectively; Z, L, C are the impedance, inductance and capacitance, respectively; $\omega, \omega \mathrm{m}$ are the electrical and mechanical angular frequencies, respectively; $\mathrm{T}$ is the torque; $\mathrm{J}, \mathrm{K}$ are the inertia and stiffness, respectively; $p$ is the number of pair poles pairs; and $\psi \mathrm{r}$ is the amplitude of the rotor flux. The parameters of the wind energy conversion system PMSG are listed in Table A.

\subsubsection{Testing the Controllers with a Step Change} In the simulation, at the 10th second the speed is changed, once from 10 to $12 \mathrm{~m} / \mathrm{sec}$. then reduced after $10 \mathrm{sec}$. to be $8 \mathrm{~m} / \mathrm{sec}$. The DC link voltage setpoint is $1500 \mathrm{v}$. The PMSG simulation results 
using PI and Fractional order PI [25] controllers obtained by the GWO is compared to each other. Equation (7) presents the cost function.

$O b j=\int\left(v_{d c_{r e f}}-v_{d c}\right)^{2} d t+\int\left(\omega_{r_{-} r e f}-\omega_{r}\right)^{2} d t$

Where $v_{d c_{r e f}}$ is the reference value for the DC link voltage and $\omega_{r_{-} \text {ref }}$ is the reference for the electrical angular speed.
Table 4. Transient response obtained by PI and FOPI controllers.

\begin{tabular}{|l|l|l|}
\hline \multicolumn{1}{|c|}{ the rotor speed $\left(\omega_{r}\right)$} & PI & FOPI \\
\hline Maximum percent overshoot $(\%)$ & 2.35 & 0.39 \\
\hline Maximum percent undershoot $(\%)$ & 6.5 & 1.07 \\
\hline Settling time after the overshoot $(\mathrm{sec})$. & 5.76 & 4.00 \\
\hline Settling time after the undershoot $(\mathrm{sec})$. & 6.21 & 4.15 \\
\hline \multicolumn{1}{|c|}{ DC voltage $\left(\mathrm{V}_{\mathrm{dc}}\right)$} & PI & FOPI \\
\hline Maximum percent overshoot $(\%)$ & 1.2 & 0.87 \\
\hline Maximum percent undershoot $(\%)$ & 1.7 & 1.43 \\
\hline Settling time after the overshoot $(\mathrm{sec})$. & 4.6 & 4.03 \\
\hline Settling time after the undershoot $(\mathrm{sec})$. & 5.62 & 5.30 \\
\hline
\end{tabular}
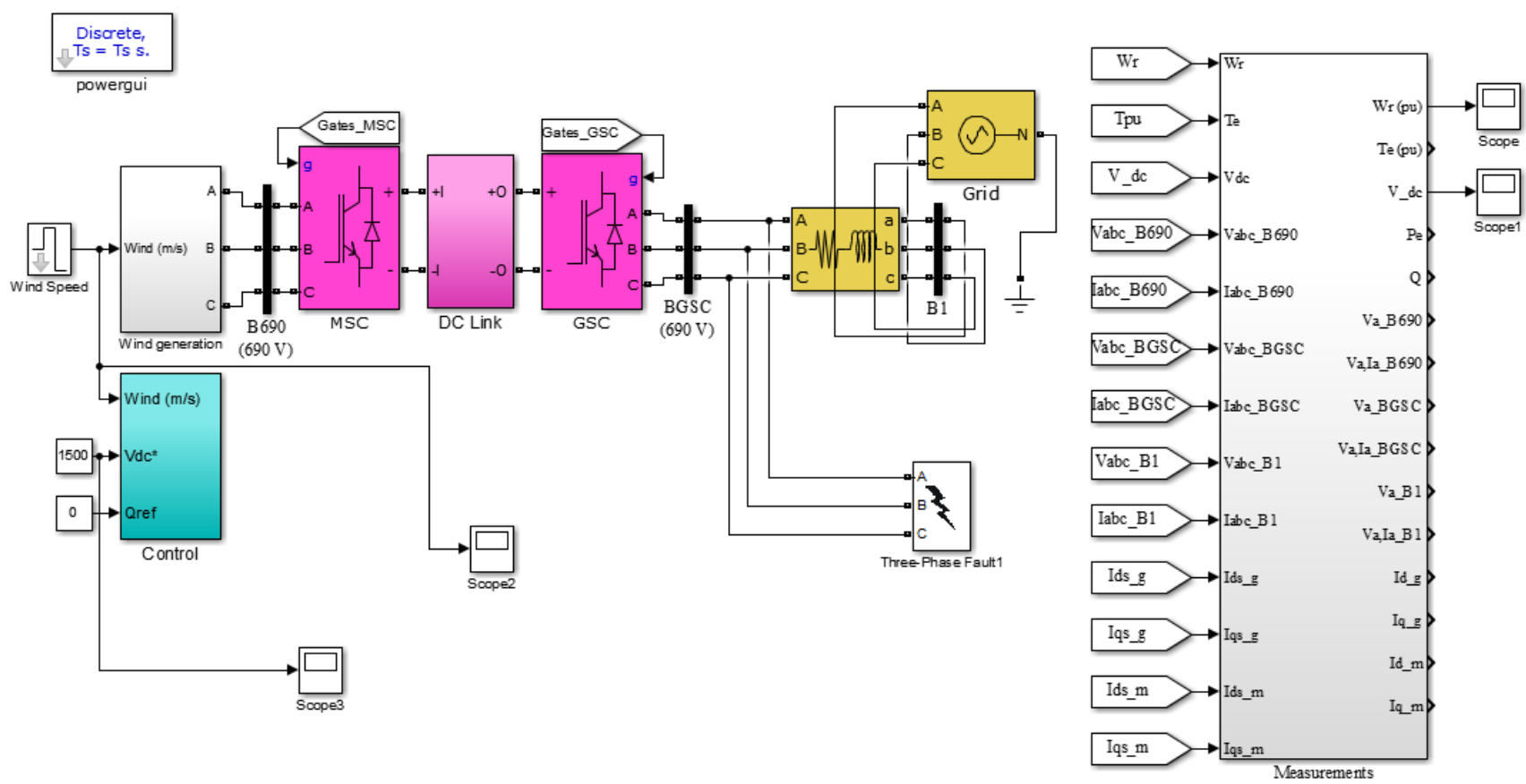

Fig. 10: The simulation for 1.5 MW PMSG using MATLAB/SIMULINK

Figure 11 shows the rotor speed profile in PU with PI and FOPI controllers parameters obtained using GWO, the graph is started at $8 \mathrm{sec}$ to neglect the starting period transients. It can be noticed from Figure 11 and Table 4 that the speed results using FOPI controller has the lower overshoot percent of $0.39 \%$ with faster settling time of $4.0 \mathrm{sec}$. when it is compared to traditional PI controller which is being used, the PI controller has an overshoot percent of $2.35 \%$ with slower settling time of $5.76 \mathrm{sec}$, so it has slower response than the FOPI response. for the second disturbance for the system "the undershoot", it can be noticed that the maximum percent undershoot using the FOPI controller tuned by GWO, is smaller (1.07\%) compared to its counterpart PI controller (6.61\%), also FOPI has a faster settling time of $4.15 \mathrm{sec}$. compared to the PI controller, which its settling time was $6.21 \mathrm{sec}$.

The DC link voltage is shown in Figure 12, its set point value is 1500v. From Figure 12 and Table 4, it can be noticed that The DC link voltage response settles faster with the FOPID controller with 4.03 sec. FOPI controller has lower overshoot of $0.87 \%$ compared to the PI controller which has an overshoot of $1.2 \%$ and settling time of $4.60 \mathrm{sec}$. For the second disturbance of undershoot occurrence, it is noticed that the maximum percent undershoot, obtained using the FOPI controller is smaller which has a value of $1.43 \%$ and faster in its settling time with $5.3 \mathrm{sec}$., if it compared with the rival values obtained by the PI controller tuned with GWO which has an under 
shoot of $1.7 \%$ with larger settling time of $5.62 \mathrm{sec}$. The less maximum overshoot and settling time the low voltage ride through capability of the PMSG responses of the generator speed and DC link voltage obtained by the FOPI controller improves

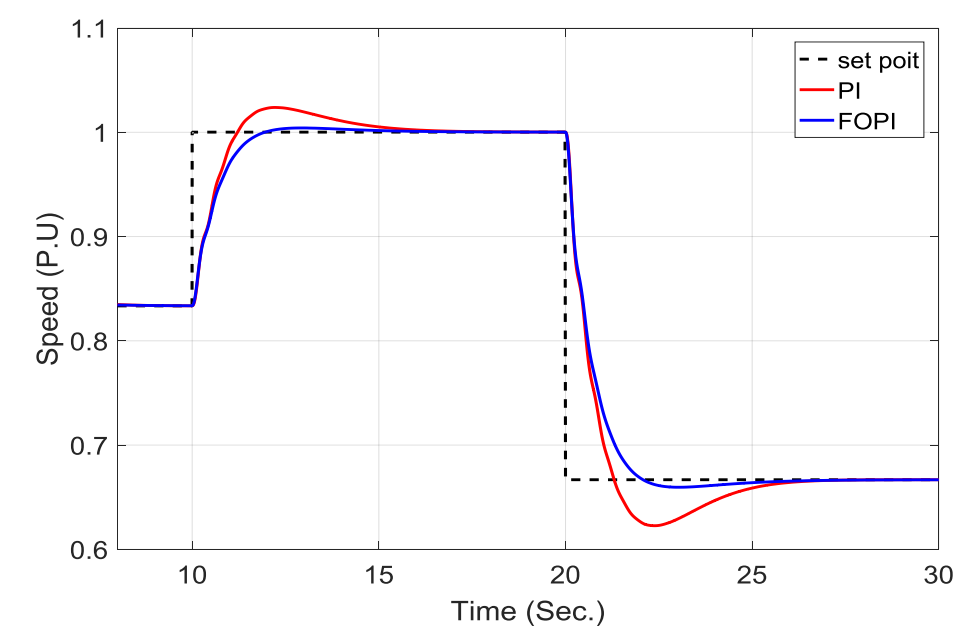

Fig. 11: The rotor speed ( $\omega r)$, in per unit, response obtained using PI and FOPI contro llers.

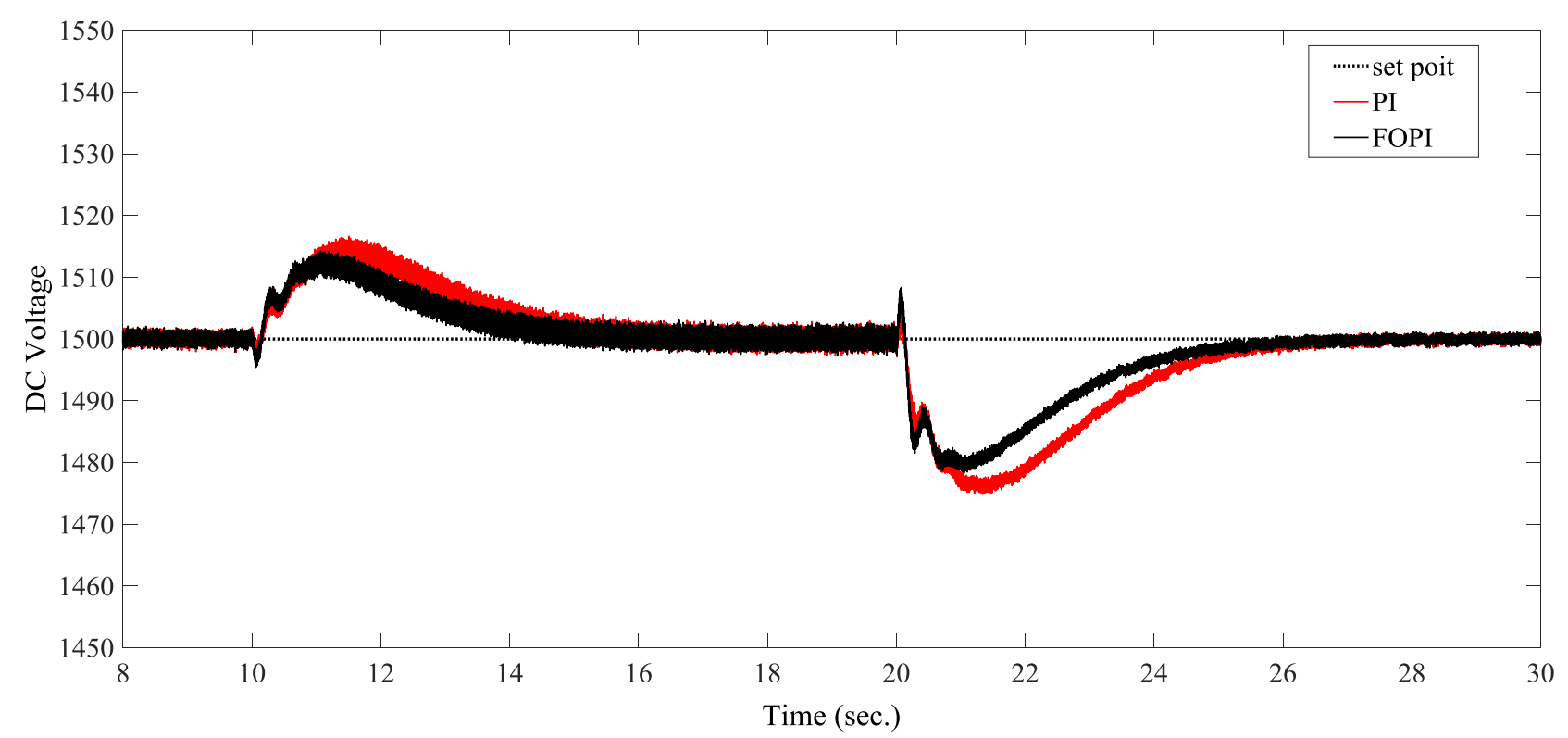

Fig. 12: The DC voltage (v.) response obtained using PI and FOPI.

High frequency ripples in the DC voltage (Figure 12) caused by the harmonics associated with the machine (generator) side rectifier.

\subsubsection{Testing the Controller Performance with Symmetrical Three Phase Fault}

The PMSG model is tested with a disturbance of symmetrical three phase to ground fault for a duration of 5 cycles, which has been occurred at the instant of $10 \mathrm{sec}$. In fault cases, there unbalance in power between the load and the generated one will accelerate the rotor speed as depicted in Figure 13. 


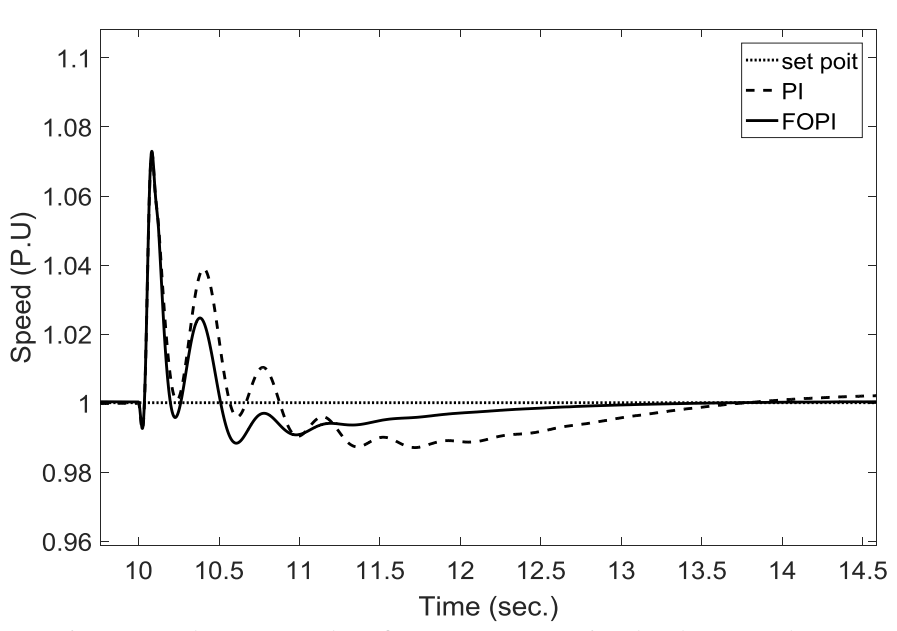

Fig.13: the speed after symmetrical three phase short circuit

It can be noticed, form Figure 13 that both controllers have the same overshoot percent may due to that both rotor has the same kinetic energy stored, at the fault the enegizes with the same amount of energy, but PI controller has here the lower settling time than usual in FOPI controller.

Figure 14 shows the DC link voltage response, that wind turbine PMSG retrieves its initial (sepoint) value rapidly, with lower overshoot for the FOPI controller parameters tuned by GWO compared to the PI controller.

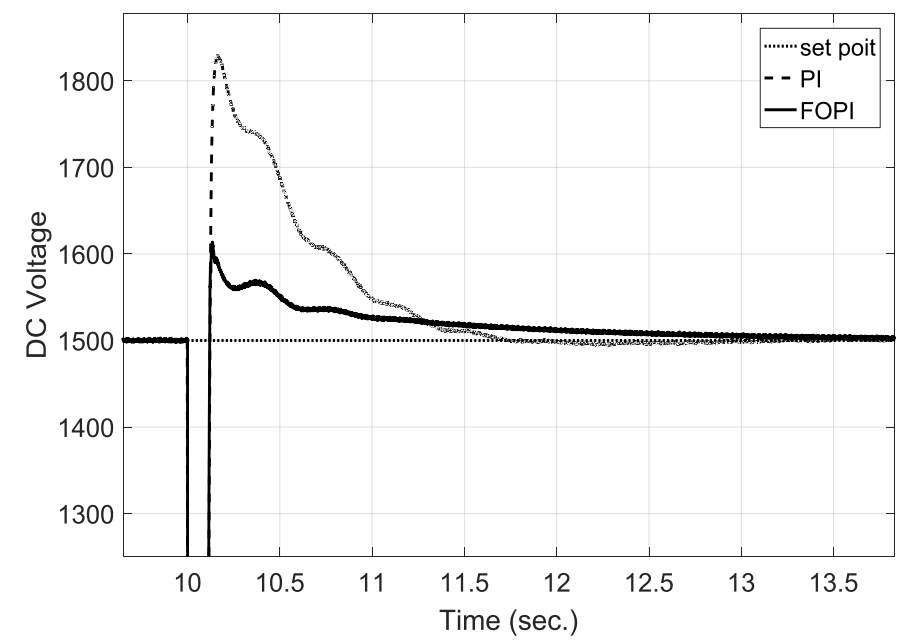

Fig. 14: The DC voltage (v.) profile obtained by PI and FOPI controllers after the symmetrical fault occurrence.

Symmetrical fault Three phase fault stating at 10 sec. and lasts for 5 cycles (i.e. the periodic time is $20 \mathrm{msec}$. so the fault clearing occurred at $10.1 \mathrm{sec}$.) at the grid side converter

The DC link voltage dropped to zero voltage which may cause the wind turbine to be forced outage from the network, the overshoot caused by the PI reached to a high value $21.33 \%$ while the overshoot reached to $7.33 \%$, but the settling time of the PI controller was about $1.5 \mathrm{sec}$. while the FOPI controller took $2.5 \mathrm{sec}$. to settle after the three phase fault disturbance.

\subsubsection{Testing the Controller Performance with Asymmetrical Single Line to Ground Fault}

Asymmetrical grid faults such as single line to ground happen more often than the symmetrical faults. During the asymmetrical grid fault, there will be a negative-sequence voltage, which can lead to second-order harmonics in the injected currents that has an effect the DC link voltage.

The fault occurs at the instant of $10 \mathrm{sec}$. and lasts for 5 cyles as in the previous case, both DC link voltage and speed are shown in Figures 15, 16 and 17.

Figure 15 shows the DC voltage after fault occurrence. Ripples may be due to the asymmetrical components of the single line to ground (phase A to ground) the overshoot was $7.33 \%$ with settling time of about $1.2 \mathrm{sec}$. for the conventional PI controllers, while the overshoot caused by the FOPI controllers was $1.33 \%$ and the voltage is settled directly after fault clearing.

Figure 16 shows the speed after the asymmetrical fault. There is an overshoot with a very small amount, which means that this type of fault has no significant effect on the speed curve, also, may be due to the slowness of such mechanical system. After zooming the speed profile at the instant of fault occurrence, the PI controller has a higher overshoot with larger settling time than its rival FOPI controller system.

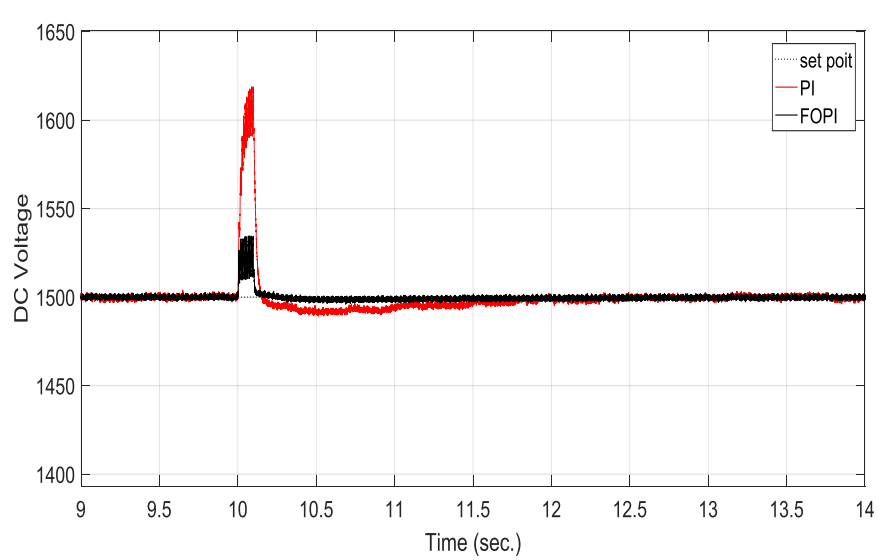

Fig. 15: The DC voltage (v.) response obtained by PI and FOPI controllers after the asymmetrical fault occurrence. 


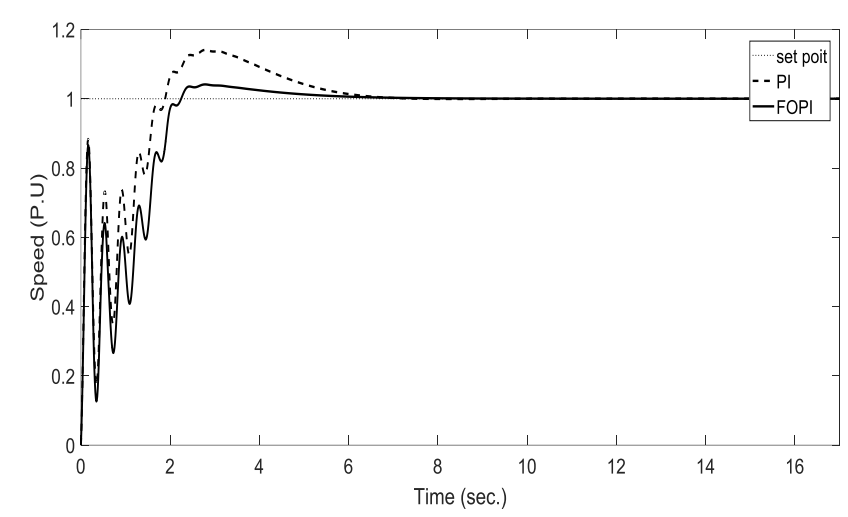

Fig. 16: The rotor speed ( $\omega r$ ) response obtained by PI and FOPI controllers after the asymmetrical fault occurrence.

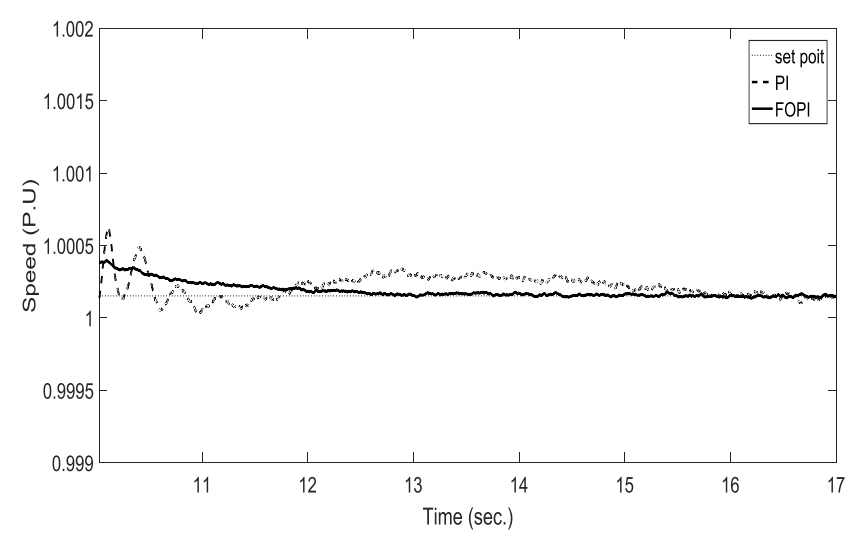

Fig. 17: Zooming on the rotor speed ( $\omega r$ ) response starting at $10 \mathrm{sec}$. obtained by PI and FOPI controllers after the asymmetrical fault occurrence.

\section{Conclusions}

In this paper, a PID controller is introduced to control the wind turbine PMSG. Also, the FOPID controller is introduced, to obtain the better optimization algorithm to be used in this paper for PI and FOPI controller parameters optimization. The performance analysis obtained from the PMSG wind turbine using PI controller compared with it rival FOPI in case of step changes in wind speed, also, the system tested under abnormal conditions such as symmetrical three phase to ground fault and asymmetrical single line to ground fault.

\section{APPENDIX A}

Table A: The PMSG parameters

\begin{tabular}{|l|c|l|c|}
\hline Base power $P_{b}(\mathrm{MVA})$ & 1.5 & Rated generator power (pu) & 1 \\
\hline Base voltage $V_{b}(\mathrm{~V})$ & $690 / \sqrt{3}$ & Rated generator line voltage & 1 \\
\hline Base frequency $f_{b}(\mathrm{~Hz})$ & 11.5 & Rated generator speed (pu) & 1 \\
\hline Number of pair poles P & 40 & $\begin{array}{l}\text { Inertia of the wind turbine } \\
(\mathrm{pu})\end{array}$ & 4.8 \\
\hline $\begin{array}{l}\text { Nominal wind turbine mechanical } \\
\text { power (pu) }\end{array}$ & 1.1 & $\begin{array}{l}\text { Generator inductance in the } \\
\text { quadrature frame (pu) }\end{array}$ & 0.7 \\
\hline Nominal wind turbine speed (pu) & 1.2 & $\begin{array}{l}\text { Generator stator resistance } \\
\text { (pu) }\end{array}$ & 0.01 \\
\hline $\begin{array}{l}\text { Generator inductance in the direct } \\
\text { frame (pu) }\end{array}$ & 0.7 & $\begin{array}{l}\text { Flux of the permanent } \\
\text { magnets (pu) }\end{array}$ & 0.9 \\
\hline Inertia of PMSG (pu) & 0.5 & DC-link capacitance (pu) & 1 \\
\hline Shaft stiffness (pu) & 2 & Line inductance (pu) & 0.1 \\
\hline Rated generator torque (pu) & 1 & Rate wind speed $(\mathrm{m} / \mathrm{s})$ & 12 \\
\hline
\end{tabular}

\section{References}

[1] Boghdady, T. A., M. M. Sayed, and EE Abu Elzahab. "Maximization of generated power from wind energy conversion system using a new evolutionary algorithm." Renewable energy 99 (2016): 631-646.

[2] Zahran, O. H., T. A. Boghdady, and M. M. Sayed. "Improving the Controller Performance for a Grid Connected Wind Farm." (2018): 306.

[3] Boghdady, T. A., M. M. Sayed, and Howaida M. Ragab. "Wind Energy Conversion System Oscillations Damping Using a Proposed Mutation Operator for LBBO-DE Algorithm." 2019 21st International Middle East Power Systems Conference (MEPCON). IEEE, 2019.

[4] Masters, G. M. (2013). Renewable and efficient electric power systems. John Wiley \& Sons.

[5] Bazmi, A. A., \& Zahedi, G. (2011). Sustainable energy systems: Role of optimization modeling techniques in power generation and supply-A review. Renewable and sustainable energy reviews, 15(8), 3480-3500.

[6] Evans, A., Strezov, V., \& Evans, T. J. (2009). Assessment of sustainability indicators for renewable energy technologies. Renewable and sustainable energy reviews, 13(5), 1082-1088.

[7] Nguyen, Tuan Ngoc Anh, et al. "Implementation of Equilibrium Optimizer Algorithm for MPPT in a wind turbine with PMSG." WSEAS Transactions on Systems and Control 16 (2021): 216-223.

[8] Hassan, Salmi, et al. "PSO-Backstepping Design for Sharing Active and Reactive Power in Grid-Connected DFIG based Wind Turbine." WSEAS Transactions on Circuits and Systems 20 (2021): 33-42.

[9] Chehouri, A., Younes, R., Ilinca, A., \& Perron, J. (2015). Review of performance optimization 
techniques applied to wind turbines. Applied Energy, 142, 361-388.

[10] Ziegler, J. G., \& Nichols, N. B. (1993). Optimum settings for automatic controllers. Journal of dynamic systems, measurement, and control, 115(2B), 220-222.

[11] Jabban, T. M., Alali, M. A. E., Mansoor, A. K. Z., \& Hamoodi, A. N. (2012). Enhancing the step response curve for rectifier current of HVDC system based on artificial neural network controller. Journal of King Saud University-Engineering Sciences, 24(2), 181192.

[12] Blum, C., \& Roli, A. (2003). Metaheuristics in combinatorial optimization: Overview and conceptual comparison. ACM Computing Surveys (CSUR), 35(3), 268-308.

[13] Glover, F. (1986). Future paths for integer programming and links to artificial intelligence. Computers \& operations research, 13(5), 533-549.

[14] Yang, X. S. (2010). Engineering optimization: an introduction with metaheuristic applications. John Wiley \& Sons.

[15] Holland, J. H. (1975). Adaptation in natural and artificial systems. An introductory analysis with application to biology, control, and artificial intelligence. Ann Arbor, MI: University of Michigan Press.

[16] Kennedy, R. (1995, November). J. and Eberhart, Particle swarm optimization. In Proceedings of IEEE International Conference on Neural Networks IV, pages (Vol. 1000).

[17] Geem, Z. W., Kim, J. H., \& Loganathan, G. V. (2001). A new heuristic optimization algorithm: harmony search. Simulation, 76(2), 60-68.

[18] Mirjalili, Seyedali, Seyed Mohammad Mirjalili, and Andrew Lewis. "Grey wolf optimizer." Advances in engineering software 69 (2014): 46-61.

[19] Tarek A. Boghdady, MM sayed, and Essam A Elzahab. "Maximization of Wind Energy Conversion Using Sliding Mode Control Tuned By Linearized Biogeography-Based Optimization." Journal of Electrical Engineering 15.4 (2015): 69-74.

[20] Tarek A. Boghdady, MM sayed, and Essam A Elzahab. "An Analysis of Migration Models for Linearized Biogeography-Based Optimization Applied for PID Tuning Problem." Journal of Electrical Engineering 16.1 (2016): 257-268.
[21] Heier, Siegfried. Grid integration of wind energy conversion systems. Wiley, 1998.

[22] Garrido, J., Vázquez, F., \& Morilla, F. (2012). Centralized multivariable control by simplified decoupling. Journal of process control, 22(6), 1044-1062.

[23] Cha, C., Kim, S. Y., Cao, L., \& Kong, H. (2010). Decoupled control of stiffness and permeability with a cell-encapsulating poly (ethylene glycol) dimethacrylate hydrogel. Biomaterials, 31(18), 4864-4871.

[24] Boghdady, T. A., Alajmi, S. N., Darwish, W. M. K., HASSAN, M. M., \& Seif, A. M. (2021). A Proposed Strategy to Solve the Intermittency Problem in Renewable Energy Systems Using A Hybrid Energy Storage System. WSEAS Transactions on Power Systems, 16, 41-51.

[25] Sarwar, Imran S. "Modelling and Motion Control of BLDC motor for Pan tilt Platform." WSEAS Transactions on Systems and Control 16 (2021): 183-193.

\section{Creative Commons Attribution License 4.0 (Attribution 4.0 International, CC BY 4.0)}

This article is published under the terms of the Creative Commons Attribution License 4.0 https://creativecommons.org/licenses/by/4.0/deed.en _US 